\title{
TÍTULOS DE CRÉDITO: UMA RELAÇÃO ENTRE A SEGURANÇA JURÍDICA E A JUSTIÇA NAS TEORIẢS DA CRIAÇÃO E EMISSÃ̃
}

\section{CREDIT TITLES: A RELATIONSHIP BETWEEN LEGAL CERTAINTY AND JUSTICE IN THE THEORIES OF CREATION AND ISSUANCE}

\begin{abstract}
${ }^{1}$ Wallace Fabrício Paiva Souza
${ }^{2}$ Jean Carlos Fernandes

\section{RESUMO}

Os títulos de crédito desempenham um papel fundamental no mercado, por permitirem que o crédito circule de forma rápida e segura, podendo-se dizer que foram a maior contribuição do Direito Empresarial para a formação da economia moderna. Contudo, justamente pelo fato de permitirem essa circulação do crédito de forma rápida e segura, podem surgir alguns questionamentos. Quando se analisam as teorias da criação e da emissão no âmbito dos títulos de crédito, verifica-se que no direito brasileiro pode ocorrer de uma pessoa que teve um título de crédito furtado ser obrigado a pagá-lo, por exemplo. E, nesse contexto, pode surgir um conflito entre a segurança jurídica e a certeza, de um lado, e a equidade e a justiça, de outro. As primeiras respondem à necessidade dos cidadãos de terem organicidade e unidade do sistema, de forma que o direito reduza a realidade social em esquemas simples e formais. As segundas, por sua vez, respondem à necessidade de buscar o máximo de adequação possível entre o direito e a realidade, de modo que o direito não seja imutável e insensível. No entanto, nem sempre é possível conciliá-los de forma plena, sendo necessário um equilíbrio entre eles na situação de fato. Dessa forma, importante analisar essa relação no âmbito das teorias da criação e da emissão, notadamente quando um título circula sem a vontade do subscritor e ele tem que cumprir com a obrigação. Relevante essa análise, por serem tanto a segurança jurídica e certeza como a justiça e equidade exigências do direito. Caso não haja um equilíbrio, corre-se o risco de prejudicar o mercado e consequentemente toda a economia de um país ou que haja decisões que gerem uma sensação de injustiça, sendo prejudicial à credibilidade do Poder Judiciário. Ao final do trabalho, então, espera-se justificar a necessidade desse equilíbrio, principalmente pela importância dos títulos de crédito e os reflexos que geram na sociedade. Como método de pesquisa, foi utilizado o exploratório, de modo que o objeto foi estudado por meio de coleta e estudo de doutrina, artigos científicos e dissertações que retratam o tema em questão.
\end{abstract}

Palavras-chave: Títulos de crédito, Segurança jurídica, Justiça, Teoria da criação, Teoria da emissão

\section{ABSTRACT}

Securities play a key role in the market once they allow the credit circulate quickly and safely. It could be said that securitues have been the greatest contribution of business law for the formation of the modern economy. However, precisely because they permit a quick ad safe credit circulation, there may be some questions about the subject. When we analyze the theories about creation and issuance of the securities, it appears that under Brazilian law it is possible

\footnotetext{
${ }^{1}$ Mestrado em andamento em Direito na Faculdades Milton Campos - FMC, Minas Gerais, MG, (Brasil). .E-mail.: wallacefabricio1@ hotmail.com

${ }^{2}$ Pós-Doutor pela Universidade de Coimbra, UC, Coimbra, (Portugal). Professor da Faculdade de Direito Milton Campos, FDMC, Minas Gerais, MG.(Brasil). E-mail.: jeancarlos@ jeancarlosfernandes.com.br
}

Revista Brasileira de Direito Empresarial | e-ISSN: 2526-0235|Minas Gerais| v. 2 | n. 1 | p.103-129| Jul/Dez 2015. 
that a person who had a debt claim stolen be required to pay for it, for example. And in this context, a conflict may arise between legal certainty and certainty itself on one hand, and equity and justice on the other. The first ones answer the need of citizens to have organic structure and system drive so that the right to reduce the social reality in simple and formal schemes. The latter ones, in turn, respond to the need to seek the maximum possible match between the law and reality, so that the law is not immutable and insensitive. However, it is not always possible to reconcile them fully, requiring a balance between them in fact situation. Thus, important to examine this relationship in the context of theories of creation and issue, especially when a title circulates without the will of the applicant and he has to fulfill the obligation. Relevant to this analysis, because they are both legal certainty and certainty as justice and equity requirements of law. If there is no balance, we run the risk of harming the market and therefore the entire economy of a country or that there are decisions that generate a sense of injustice, being harmful to the credibility of the judiciary. At the end of the work, then, it is expected to justify the need for this balance, particularly the importance of debt securities and the consequences that generate in society. As a research method, the exploration was used, so that the object has been studied by collecting and doctrine study, scientific articles and dissertations that portray the theme.

Keywords: Credit titles, Legal certainty, Justice, Theorie of creation, Theorie of issuance

\section{INTRODUÇÃO}

Os títulos de crédito são um tema de grande relevância não só para o Direito, mas para toda a sociedade, notadamente pelo papel que desempenham no mercado. Inclusive, falase nos títulos de crédito como a maior contribuição do Direito Empresarial para a formação da economia moderna.

O crédito em si é essencial para que uma economia de um país consiga se desenvolver, e os títulos de crédito permitem que ele circule de forma rápida, simples e segura. Verifica-se, assim, que uma das principais características desses títulos para que se tenha essa importância é a segurança jurídica e a certeza que deles emana.

Contudo, há momentos nos quais a certeza de que os títulos de crédito são dotados, visando à segurança jurídica, pode gerar num caso concreto uma sensação de injustiça, como nos casos em que um título é furtado e um terceiro de boa-fé tem o direito de cobrá-lo, observada a aplicação das teorias da criação e emissão.

Faz-se necessário, assim, o estudo dessas questões, de modo que o presente trabalho almeja analisar a relação entre a segurança jurídica e a justiça no âmbito dos títulos de crédito, notadamente na aplicação das referidas teorias. 
Para a condução deste trabalho, então, foi utilizado o método exploratório, de modo que o objeto foi estudado por meio de coleta e estudo de doutrina, artigos científicos e dissertações que retratam o tema em questão.

Dessa forma, dividiu-se a pesquisa em 4 (quatro) partes. Partiu-se da análise da importância dos títulos de crédito, contextualizando o tema na atualidade. Foi demonstrado como os títulos de crédito surgiram e o seu papel no mercado, traçando breves anotações sobre sua evolução e suas principais características. Após, passou-se a análise da segurança jurídica no âmbito dos títulos de crédito e o papel da formalidade nas relações do mercado. Fez-se, assim, uma análise do instituto da segurança jurídica e suas principais características, demonstrando também como a formalidade é importante não só para os títulos de crédito, mas nas relações de mercado no geral.

Dando continuidade, fez-se um estudo de justiça e equidade, para que pudesse ser estabelecida a relação com a segurança jurídica e a ideia de certeza. Foram abordados também os principais aspectos da boa-fé, importantes para o estabelecimento da referida relação. Por fim, foi estabelecida a relação entre a segurança jurídica e a justiça, partindo da análise das teorias da criação e da emissão no âmbito dos títulos de crédito.

Espera-se que ao final sejam atingidos os objetivos propostos.

\section{A IMPORTÂNCIA DOS TÍTULOS DE CRÉDITO E BREVE CONTEXTUALIZAÇÃO SOBRE O TEMA NA ATUALIDADE}

Os títulos de crédito, que surgiram na Idade Média, eram documentos utilizados para a realização de contratos de câmbio e troca de moedas entre as cidades-estado. E, nessa fase inicial, apenas eram emitidas para facilitar a troca de moedas, tratando-se da letra de câmbio e da nota promissória (PATROCÍNIO, 2009, p. 227).

Em certo momento da história, fazia-se necessário operações mercantis com mais dinamismo, e o crédito, que significa crença ou confiança, possibilitava que o efetivo pagamento fosse em momento posterior, mas já antecipando o recebimento da mercadoria ou serviço almejado. Contudo, esse direito ao crédito precisava ser exteriorizado, o que ocorreu inicialmente na forma cartular, surgindo o título de crédito (FERNANDES, 2015, p. 193). Importante destacar que embora nem todo documento seja um título de crédito, "todo título de crédito é, antes de tudo, um documento no qual se consigna a prestação futura prometida pelo devedor" (BORGES, 1976, p. 8). 
Nas palavras de Tullio Ascarelli, "se nos perguntassem qual a contribuição do direito comercial na formação da economia moderna, outra não poderia talvez apontar que mais tipicamente tenha influído nessa economia do que o instituto títulos de crédito" (ASCARELLI, 2013, p. 33). Afinal, o crédito, que tem como pressupostos os conceitos de confiança e tempo, está diretamente relacionado ao desenvolvimento econômico de uma sociedade.

Como explicado por Jairo Saddi, "um dado país não consegue se desenvolver sem um amplo e estável mercado de crédito.” (SADDI, 2007, p. 17). Diz ainda que "desenvolvimento econômico sustentável de longo prazo que permita o combate à pobreza, depende de um mercado de crédito crescente que inclua a todos.” (SADDI, 2007, p. 17). João Eunápio Borges diz que os títulos de crédito tiveram um papel mais importante que

todas as minas do mundo para o enriquecimento das nações. Por meio deles, o direito consegue vencer tempo e espaço, transportando com facilidade bens distantes e materializando no presente - atualizando-as - as possíveis riquezas futuras. (BORGES, 1976, p. 9).

E um dos elementos principais para o âmbito deste trabalho é ter em mente que essa importância dos títulos de crédito se deu em face da forma segura com que permitem o crédito circular. Manuel Broseta Pont (2007, p. 401), inclusive, ressalta que os títulos de créditopermitem a transmissibilidade dos direitos de conteúdo patrimonial de forma rápida, simples e segura.

A primeira definição de títulos de crédito verificada na doutrina foi feita por um jurista germânico chamado Brunner, que assim os definiu: "documentos de um direito privado que não pode ser exercido, senão pela apresentação do título” (LUCCA, 1979, p. 11). Todavia, tratando-se de um conceito amplo, que nas palavras de Tullio Ascarelli envolve "todos os documentos cuja apresentação é necessária para o exercício do direito a que referem" (ASCARELLI, 2013, p. 57), Cesare Vivante criou a definição mais conhecida, no sentido de que "título de crédito é um documento necessário para o exercício do direito literal e autônomo nele mencionado” (REQUIÃO, 2008, p. 371).

Sendo assim, verificam-se como características ou princípios dos títulos de crédito a literalidade, autonomia e cartularidade, as quais Rubens Requião define da seguinte forma:

a) Literalidade. O título é literal porque sua existência se regula pelo teor de seu conteúdo. O título de crédito se enuncia em um escrito, e somente o que 
está nele inserido se leva em consideração; uma obrigação que dele não conste, embora sendo expressa em documento separado, nele não se integra.

b) Autonomia. Diz-se que o título de crédito é autônomo (não em relação à sua causa como às vezes se tem explicado), mas, segundo Vivante, porque o possuidor de boa-fé exercita um direito próprio, que não pode ser restringido ou destruído em virtude das relações existentes entre os anteriores possuidores e o devedor. Cada obrigação que deriva do título é autônoma em relação às demais.

c) Cartularidade (documento necessário). O título de crédito se assenta, se materializa, numa cártula, ou seja, num papel ou documento. Para o exercício do direito resultante do crédito concedido torna-se essencial a exibição do documento. $\mathrm{O}$ documento é necessário para o exercício do direito de crédito. Sem a sua exibição material não pode o credor exigir ou exercitar qualquer direito fundado no título de crédito. Vivante, com esse conceito, substitui o vulgar, que combate, pelo qual se afirma que o direito está incorporado ao título. (REQUIÃO, 2008, p. 371/372).

Além dessas características, alguns títulos ainda intensificam uma qualidade particular, que é a independência. Esses títulos "não se integram, não surgem nem resultam de nenhum outro documento. Não ligam ao ato originário de onde provieram” (REQUIÃO, 2008, p. 372). É uma característica especial, porque há títulos vinculados aos atos que lhes deram origem.

Importante destacar também a característica da abstração, que ocorre quando o título pode circular sem ligação com a causa que lhe deu origem. Essa característica também não é essencial (REQUIÃO, 2008, p. 372).

Contudo, hoje se fala numa nova teoria para os títulos de crédito, uma vez que não faz mais sentido falar em "cartularidade" como requisito essencial, considerando os inúmeros títulos de crédito escriturais, imaterializados.

Estabelecem-se, então, algumas reflexões. Será que o conceito criado por Vivante atende a atual realidade dos títulos de crédito? ${ }^{1}$

Além disso, pergunta-se quanto aos princípios da teoria clássica, quais sejam, cartularidade, literalidade e autonomia. Eles subsistiriam à atual realidade dos títulos de crédito? Como resposta, tem-se a necessidade de readequação dos princípios cambiários, com o objetivo de aplicá-los aos títulos de crédito materializados numa cártula ou não (FERNANDES, 2015, p. 213). Afinal, os chamados títulos de crédito escriturais, que apenas existem no meio digital, são atualmente "a grande massa dos créditos" (COELHO, 2010). Como se observa em consulta ao site da CETIP S.A., que é a integradora do mercado financeiro, o estoque de títulos de crédito escriturais registrados em 04/03/2015 era de $\mathrm{R} \$ 793.619 .488 .644,14$ (setecentos e noventa e três bilhões, seiscentos e dezenove milhões, 
quatrocentos e oitenta e oito mil, seiscentos e quarenta e quatro reais, e quatorze centavos) (CETIP, 2015). É mais adequado, assim, falar no princípio da documentabilidade, que abarcará tanto os títulos cartulares como os não cartulares (FERNANDES, 2015, p. 214).

Estabelecidos esses pressupostos, passa-se a análise da segurança jurídica e o papel da formalidade no âmbito dos títulos de crédito.

\section{A SEgURANÇA JURÍdicA NO ÂMBITO DOS TÍTULOS DE CRÉDITO E O PAPEL DA FORMALIDADE}

A necessidade de certeza no direito e segurança na sua realização faz com que sejam criados institutos que satisfaçam essas exigências (ASCARELLI, 2013, p. 35). Nesse contexto, estão os títulos de crédito, cuja principal finalidade é estabelecer a circulação do crédito com facilidade e segurança, servindo como meio de prova entre as partes envolvidas. Importante, então, analisar os conceitos de segurança jurídica e certeza, que os títulos de crédito trazem, e o papel da formalidade.

A compreensão da segurança jurídica está intimamente ligada a de certeza, que é: “ 1 qualidade do que é certo. 2 persuasão íntima; convicção; evidência, [...] evidentemente; sem dúvida." (CEGALLA, 2005, p. 185). E, como princípio, ela deve ser uma das balizas para tudo que esteja relacionado ao direito, seja relações entre o Estado e o cidadão, seja entre os próprios cidadãos, falando-se até no direito à segurança jurídica (MOREIRA, 2010, p. 12).

Tércio Sampaio Ferraz Júnior (2007, p. 140/141) até estabelece uma diferença entre os valores da certeza e segurança jurídica, de modo que esta seja referente aos destinatários das normas, enquanto àquela referente a uma coerente apreensão das situações de fato, evitando-se ambiguidades e vaguidade de sentido. Contudo, para o âmbito deste trabalho, é importante ter em mente que ambas estão diretamente relacionadas a decidibilidade dos conflitos, atuando conjuntamente.

\footnotetext{
${ }^{1}$ Para responder a pergunta, propõe-se um novo conceito para os títulos de crédito, adotando a teoria contemporânea e não mais clássica: "Título de crédito é o documento, cartular ou eletrônico, indispensável para o exercício e a transferência do direito cambial literal e autônomo nele mencionado ou registrado em sistema de custódia, transferência e liquidação legalmente autorizado, bem como para a captação de recursos nos mercados financeiro ou de capitais, dotado de executividade por si ou por certidão de seu inteiro teor emitida pela instituição registradora." (FERNANDES, 2015, p. 212/213).
} 
Historicamente, tem-se como exemplo mais antigo dos primeiros traços da segurança jurídica no Digesto, no qual Ulpiano estabeleceu que seriam válidos todos os atos de um escravo que, ocultando essa sua característica, exerceu as atividades de pretor. Em prol da segurança jurídica, como se tratava de um pretor nomeado, embora escravo, os seus atos não deveriam ser nulos (SILVA, 2005). Nas Constituições Brasileiras, verifica-se a segurança jurídica desde a de 1824, no art. 179, incisos III e XXVIII ${ }^{2}$, nos quais, ainda com resquício de absolutismo ao se tratar de uma Constituição outorgada, contemplou-se a sua irretroatividade e proteção ao direito adquirido.

$\mathrm{Na}$ Constituição atual, o princípio da segurança jurídica, embora não esteja expressamente previsto, é considerado um princípio constitucional com amparo no inciso XXXVI do art. $5^{\circ}$, com a seguinte redação: "a lei não prejudicará o direito adquirido, o ato jurídico perfeito e a coisa julgada” (BRASIL, 1988, Art. 5, XXXVI). Sendo assim, é dotado inclusive de caráter de cláusula pétrea, em função da disposição do art. 60, §4, IV: “Art. 60. [...] $\$ 4^{o}$ Não será objeto de deliberação a proposta de emenda tendente a abolir: [...] IV - os direitos e garantias individuais." (BRASIL, 1988, Art. 60, §4º, IV).

$\mathrm{Na}$ legislação infraconstitucional, a primeira lei a trazer expressamente o princípio da segurança jurídica foi a de n. 9.784/99, que regula o processo administrativo no âmbito da Administração Pública Federal, constando no art. 2: "A Administração Pública obedecerá, dentre outros, aos princípios da legalidade, finalidade, motivação, razoabilidade, proporcionalidade, moralidade, ampla defesa, contraditório, segurança jurídica, interesse público e eficiência." (BRASIL, 1999, Art. $2^{\circ}$ ).

Adentrando no conteúdo que a segurança jurídica expressa, fala-se em duas dimensões: objetiva e subjetiva, sendo que a primeira refere-se a valores externos que protegem o cidadão, enquanto a segunda protege o próprio cidadão. Segundo José Davi Cavalcante Moreira,

na dimensão objetiva, a proteção é oposta pelo cidadão ao Estado, sendo o cidadão protegido contra as mudanças na política estatal hábeis a prejudicar ou fragilizar seu direito à estabilidade, à previsibilidade que lhe permite planejar seus passos sem que sofra mudanças bruscas, sendo, em temos simples, uma parcela do direito à segurança, nesse caso, segurança político-

\footnotetext{
2“"Art. 179. A inviolabilidade dos Direitos Civis, e Politicos dos Cidadãos Brazileiros, que tem por base a liberdade, a segurança individual, e a propriedade, é garantida pela Constituição do Imperio, pela maneira seguinte. [...] III. A sua disposição não terá effeito retroactivo. [...] XXVIII. Ficam garantidas as recompensas conferidas pelos serviços feitos ao Estado, quer Civis, quer Militares; assim como o direito adquirido a ellas na fórma das Leis."
} 
institucional. Na dimensão subjetiva, a proteção é oposta pelo cidadão aos seus pares, sendo a proteção da confiança depositada nos negócios jurídicos e direitos em geral de que não serão, por exemplo, os contratos, ou qualquer outra relação, alterados de modo a afetar o patrimônio jurídico já consolidado. Aqui o princípio da segurança jurídica suporta os particulares, assegurando aos atos praticados sob certa regulamentação não serão afetados por outra que advenha, seria possível falar num direito à estabilidade conferido aos cidadãos. (MOREIRA, 2010, p. 12/13).

Cármem Lúcia Antunes Rocha, assim, define segurança jurídica na "garantia da estabilidade e de certeza dos negócios jurídicos, de sorte que as pessoas saibam de antemão que, uma vez envolvidas em determinada relação jurídica esta se mantém estável, mesmo se modificar a base legal sob a qual se estabeleceu” (ROCHA, 2004, p. 168).

E, nesse contexto da segurança jurídica e certeza quanto aos títulos de crédito, quem ganha um papel fundamental é a formalidade, que impõe formas para a constituição, transferência e o exercício do direito incorporado ao título. A princípio, poderia se pensar que a formalidade seria um empecilho para a dinâmica e celeridade que as atividades comerciais exigem, mas ela é de extrema importância para o desenvolvimento e o aprimoramento das relações comerciais (ARAÚJO, 2010, p. 283).

Segundo Danilo Borges dos Santos Gomes de Araújo,

a forma não significa necessariamente complexidade. A forma também pode ser simples. E são dos esquemas formais mínimos e simples, predeterminados e de prévio conhecimento das partes, que se vale a prática comercial, assim se provendo a certeza da existência do direito e a segurança da sua ulterior realização. (ARAÚJO, 2010, p. 284).

Verifica-se, então, que a formalidade tem um papel importante notadamente no Direito Empresarial, embora muitas vezes se pense ser um atraso para o ordenamento jurídico.

Inclusive, o autor Danilo Borges dos Santos Gomes de Araújo (2013, p. 4) coloca que o princípio da literalidade é o corolário do formalismo jurídico, uma vez que o direito que surge do título de crédito é consequência e dependente do teor do título.

Relacionando esses valores, então, com os títulos de crédito, como explicado por Pontes de Miranda, por serem munidos de valor documental, somente podem ser atacados por provas claras, terminantes e concludentes (MIRANDA, 2001, p. 48). E direito incerto é direito ineficaz, então essencial a segurança que os títulos de crédito trazem. Eles são, antes de tudo, documentos formais.

Tullio Ascarelli explica: 


\begin{abstract}
Essa certeza e a segurança são postas em ação através do processo de simplificação analítica do pressuposto de fato, que Rudolf Von Ihering ilustrou em páginas decisivas. É realmente um processo de simplificação analítica o documento legitimador no exercício do direito; é pelo mesmo motivo que a promessa contida no título se divorcia do destinatário e que o direito incorporado no título se torna independente da relação fundamental e, em alguns títulos, absolutamente abstrato. A par da simplificação da espécie jurídica está o formalismo jurídico, que domina em matéria e em títulos de crédito, impondo formas rigorosas para a constituição, a transferência e o exercício do direito. Os que julgam ser o formalismo jurídico um fenômeno que só ocorreu no direito primitivo, não anotaram, talvez, o renascimento de formalismo que se pode observar no direito moderno e, especialmente, no direito comercial. (ASCARELLI, 2013, p. 36).
\end{abstract}

Mesmo sem considerar os títulos de crédito, encontram-se as formas mais rigorosas justamente nas relações de comércio, quando os contratos decorrentes dessa relação passam a entrar em esquemas predeterminados. E muitas vezes isso é mais em decorrência da própria vontade das partes que da lei. Verifica-se, então, como a certeza e segurança são fundamentais para o mercado.

Sendo assim, indubitáveis os momentos nos quais se deve reiterar o caráter de certeza do direito, todavia há momentos também nos quais se pretende atenuar essa certeza para resolver equitativamente um problema concreto, mas até que ponto isso pode ser feito sem prejudicar o funcionamento do mercado? Passa-se, então, no próximo capítulo, à análise da justiça e equidade.

\title{
4 JUSTIÇA E EQUIDADE
}

A ideia de justiça é trazida por inúmeros autores e muitas vezes com sentidos diversos, variando inclusive ao longo da história. Para Aristóteles, justiça é sinônimo de virtude, sendo "aquela disposição de caráter que torna as pessoas propensas a fazer o que é justo, que as faz agir justamente e a desejar o que é justo." (ARISTÓTELES, 2001, p. 103).

Seguindo a classificação de Carolina Machado Cyrillo da Silva (2005, p. 40), essa seria a justiça universal. Do outro lado, estaria a justiça em sentido estrito, que é o elemento que ordena as relações humanas na polis, subdividindo-se na geral ou legal e particular. A geral ou legal é a conformidade da conduta de um indivíduo à lei, porém importante ressaltar que a lei para Aristóteles envolve o que está escrito e o que não está, sejam naturais ou positivas, portanto a justiça assim entendida engloba toda a moral também. A particular, por 
sua vez, tem por objetivo realizar a igualdade entre os sujeitos de uma determinada relação, podendo ser distributiva ou corretiva.

A justiça distributiva é referente ao legislador e tem por objetivo a distribuição com igualdade dos bens da polis, sendo o justo uma espécie de termo proporcional, pois como as pessoas são diferentes também devem receber de forma diferente. Já a justiça corretiva referese ao juiz, que deve tentar restaurar a ordem que foi destruída por algo, restabelecendo a igualdade. Essa ainda divide-se em duas: comutativa, que regula as transações voluntárias, trazendo proporcionalidade entre prestação e contraprestação; e reparativa, quando há dano, podendo ser estabelecida uma punição.

Há, ainda, para Aristóteles, uma outra acepção de justiça, denominada como equidade. Na análise feita por Chaim Perelman (2000, p. 156), o equitativo seria justo, mas não o legalmente justo, sendo uma correção da justiça legal.

Nas palavras de Aristóteles:

quando a lei estabelece uma regra geral e surge um caso que não é abarcado por essa regra, então é correto (visto que o legislador falhou e errou por excesso de simplicidade), corrigir a omissão, dizendo o que o próprio legislador teria dito se estivesse presente, e o que teria incluído na lei se tivesse previsto o caso em pauta. (ARITÓTELES, 2001, p. 125).

Embora a lei seja universal, é impossível que ela regule todos os casos particulares que possam acontecer, como demonstrou o período de queda do positivismo jurídico e, pela equidade, o juiz consegue corrigir essa imperfeição da lei.

Carolina Machado Cyrillo da Silva expõe sobre a equidade:

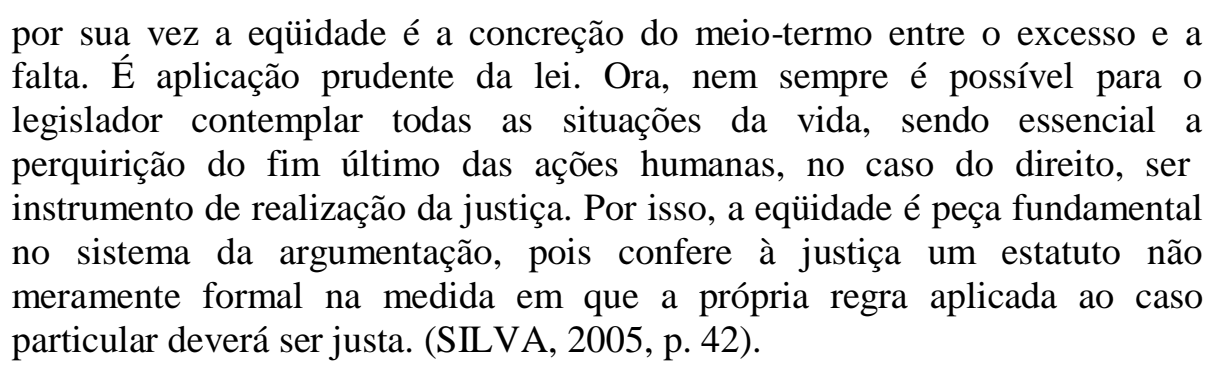

Sendo assim, a equidade corrige a obscuridade ou incompletude, de modo que o juiz tome uma decisão coerente e aceitável, isto é, dentre dos limites estabelecidos pelo ordenamento jurídico, incluindo os valores da sociedade. Chega-se, então, ao conceito de 
rlando Gomes, no sentido de que a equidade "tem a função de temperar a rigidez da norma escrita, razão pela qual é critério de aplicação da lei" (GOMES, 1996, p. 51).

Para satisfazer a equidade, os ordenamentos jurídicos num todo estabelecem mecanismos que dão discricionariedade ao juiz e reenviam a determinação do conteúdo da norma para valores sociais, bons usos e costumes, boa-fé, dentre outros (ARAÚJO, 2010, p. 270).

Especificamente sobre a boa-fé, há duas acepções: uma subjetiva e outra objetiva. A primeira, que não é um princípio, representa o estado psicológico do indivíduo no qual há a crença de ser titular de um direito que só existe aparentemente. A segunda, por sua vez, que é um princípio do ordenamento jurídico brasileiro, representa uma crença no comportamento alheio, sendo uma regra de comportamento, caracterizado por padrões de lisura e honestidade, de modo que não fruste a confiança de outra parte (ROSENVALD; FARIAS, 2011, p. 159).

A boa-fé, então, traduz-se em confiança, e em decorrência dela e da nova principiologia do direito, principalmente após a Constituição de 1988, com forte viés social, não há mais uma perspectiva absoluta no sentido de que a obrigação se esgota no dever de prestar e no correlato direito de exigir ou pretender a prestação. Fala-se, hoje, numa relação complexa, acrescida de ônus e expectativas. Há os chamados deveres de conduta, pelos quais as partes da relação jurídica compartilharão de lealdade e confiança (ROSENVALD; FARIAS, 2011, p. 167).

E o princípio da boa-fé vai além, ganhando funções interpretativa, integrativa e de controle. A interpretativa serve para aclarar o que for estipulado numa relação jurídica, a integrativa para garantir os deveres de comportamento das partes, ainda que não estejam expressos e, por fim, a de controle para que não haja abuso por algum dos sujeitos na relação (NORONHA, 1994, p. 151).

Nesse mesmo sentido da boa-fé, o ordenamento jurídico proibiu o abuso de direito, que ocorre quando o agente não viola nenhuma estrutura normativa, mas ofende sua valoração. Como explica Nelson Rosenvald e Cristiano Chaves de Farias, "conduz-se de forma contrária aos fundamentos materiais da norma, por negligenciar o elemento ético que preside a sua adequação ao ordenamento." (ROSENVALD; FARIAS, 2011, p. 181). Ou seja, não se viola a regra, mas se viola o princípio que são normas também, considerando o período pós-positivista que a sociedade se encontra.

Passa-se, então, a análise da relação da justiça e da segurança jurídica no âmbito dos títulos de crédito, observadas as teorias da criação e da emissão, que permitem essa discussão. 


\section{TÍTUlOS DE CRÉDITO E A RELAÇÃO ENTRE A SEGURANÇA JURÍDICA E A JUSTIÇA: ANÁliSE A PARTIR DAS TEORIAS DA CRIAÇÃO E DA EMISSÃo}

Ao ser elaborada uma norma legal, surge uma exigência de certeza e segurança jurídica, características essenciais no direito. Contudo, há um aparente conflito com as exigências da equidade e justiça do caso concreto. Como explica Tullio Ascarelli,

esse contraste de equidade e de certeza se encontra também, a cada passo, na interpretação da norma e nas sempre renovadas discussões metodológicas e exprime, aliás, o contraste entre a justiça do caso singular e a generalidade da norma, entre a discricionariedade do juiz e o poder do legislador. (ASCARELLI, 2013, p. 35).

No ordenamento jurídico brasileiro no que tange aos títulos de crédito, evidente esse conflito quando se discutem as teorias da criação e da emissão no direito brasileiro. A constituição da obrigação cambiária tem assento numa declaração unilateral de vontade, de modo que o

subscritor, subscrevendo, cria o título, porque perfaz o negócio jurídico unilateral (plano da existência). Se o título existe e vale, ou se não vale, é outro problema (plano da validade). Desde o momento em que, após a assinatura, ou simultaneamente à assinatura, pelo subscritor (sacador ou subscritor), ou pelo sacado, ou pelo endossante, ou pelo avalista, ou pelo interveniente, o título está na posse do alter de boa-fé, começa a sua eficácia: nasce a dívida. (MIRANDA, 2001, p. 151).

Sendo assim, a obrigação cambiária constitui-se mediante simples assinatura lançada nos títulos de crédito, tornando os coobrigados solidariamente responsáveis pelo pagamento do título, como observado no art. 47 da Lei Uniforme de Genebra, anexo I do Decreto n. $57.663 / 66^{3}$.

Newton de Lucca (1979, p. 74/80), quanto à natureza da obrigação cartular, traz inúmeras teorias, dividindo-as em lado ativo e lado passivo. No lado ativo, referente ao detentor do direito, enumeram-se, apenas a título de exemplo: teoria dos créditos sucessivos (Goldschmidt era um dos expoentes); teoria contratualística da delegação (Thaller); teoria contratualística da novação (Unger, por exemplo); teoria da sucessão particular do crédito (Renauld e Kuntze, por exemplo); teoria da cessão do crédito (Brinz); teoria da personificação do título de crédito (Schweppe e Bekker), teoria do crédito alternativo (Rocco), teoria da emissão abstrata (Arcangeli); teoria da pendência; teoria da promessa à generalidade (Reinlander e Muller, por exemplo); e, por fim, a teoria da propriedade, adotada por Tullio 
Ascarelli, dentre demais pensadores. Segundo a teoria da propriedade, "a titularidade do direito decorre não de uma transferência do direito cartular e sim, autônoma e originariamente, dos sucessivos proprietários do título pelo próprio fato de sua propriedade." (LUCCA, 1979, p. 80).

No lado passivo, o citado autor divide as teorias em três ramos: negociais, baseadas na manifestação de vontade; legais, que partem do pressuposto que a vontade não importa para o título de crédito entrar em circulação; e mistas, aplicando a negocial para emitente e tomador, e legal para terceiros de boa-fé. Nesse contexto, entram as teorias da criação e da emissão (LUCCA, 1979, p. 84/88).

É certo que, embora houvesse outras teorias quanto à constituição do direito, como as que alicerçavam a obrigação em um contrato, elas foram aos poucos perdendo espaço e hoje permanece a relativa a unilateralidade do ato. Contudo, não se pode dizer o mesmo quanto a discussão que permanece entre as teorias da criação e emissão (LUCCA, 1979, p. 84), as quais se passa a analisar.

Observada a teoria da criação, "formalizado o título, este passa a ter um valor próprio e torna-se fonte de um direito de crédito que é atribuído a um futuro detentor, qualquer que seja” (COSTA, 2007, p. 143). Sendo assim, se houver eventual desapossamento do título por qualquer motivo alheio à vontade do criador, como furto ou perda, a obrigação do criador permanece, sendo essa uma consequência grave (FERNANDES, 2015, p. 235).

Essa teoria, que tem como defensores Siegel e Kuntze, dentre outros, estabelece que o direito deriva da criação do próprio título e, por meio dele, o subscritor dispõe de seus bens. Nas palavras de Rubens Requião,

o título é como o testamento: tem valor próprio, dispensa e lhe repugna o acordo de vontades. O emissor fica ligado a sua assinatura, e obrigado para o futuro portador, credor eventual e indeterminado. Só com o aparecimento desse futuro detentor é que nasce a obrigação. Otávio Mendes criticou essa teoria, que confunde criação do título com nascimento da obrigação. Assim, para Kuntze, com a entrada em circulação do título nasce a obrigação; com a concepção do escrito nasce, apenas, o título. (REQUIÃO, 2008, p. 375).

\footnotetext{
3“Artigo 47: Os sacadores, aceitantes, endossantes ou avalistas de uma letra são todos solidariamente responsáveis para com o portador. O portador tem o direito de acionar todas estas pessoas individualmente, sem estar adstrito a observar a ordem por que elas se obrigaram.”
} 
O título, então, cria a dívida, e a única condição para que ele tenha eficácia é a posse pelo primeiro portador, observada a vontade do criador ou não (REQUIÃO, 2008, p. 375). Nos títulos de crédito escriturais a criação diverge um pouco, uma vez que apenas são criados com a inserção no sistema de registro e de liquidação financeira de ativos autorizados pelo Banco Central do Brasil. Nos títulos escriturais nominativos, garante-se a transferência voluntária ao portador legitimado (FERNANDES, 2015, p. 235).

$\mathrm{Na}$ teoria da emissão, por sua vez, que tem como adeptos Stobbe, Windscheid e Arcangeli, dentre outros, não basta a criação do título para ser gerada a obrigação do subscritor. $\mathrm{O}$ vínculo apenas se forma se houver a saída voluntária do título das mãos do subscritor, o que se denomina emissão do título. O subscritor não ficaria obrigado se comprovasse que perdeu a posse do título contra sua vontade. Se houver um furto do título, por exemplo, não haveria ainda obrigação (COSTA, 2007, p. 142).

Resta saber qual o posicionamento do direito brasileiro. Newton de Lucca já criticava o Código Civil de 1916, que foi contraditório. Ele até disse que se tem "mesmo a impressão de que os problemas em matéria de títulos de crédito são resolvidos por intuição” (LUCCA, 1979, p. 91). O Código de 1916 trouxe no seu art. 1.506: “A obrigação do emissor subsiste, ainda que o título tenha entrado em circulação contra a sua vontade" (BRASIL, 1916, Art. 1.506), adotando expressamente a teoria da criação, contudo no caput de seu artigo 521 trouxe a seguinte disposição: "Aquele que tiver perdido coisa móvel, ou título ao portador, ou a quem houverem sido furtados, pode reavê-los da pessoa que os detiver, salvo a esta o direito regressivo contra quem os transferiu” (BRASIL, 1916, Art. 521), o que é característica da teoria da emissão.

Com a oportunidade de resolver essa questão no Código Civil de 2002, foram mantidas as disposições nesse mesmo sentido, como se verifica da leitura dos artigos 905, parágrafo único, e 909, caput:

Art. 905. O possuidor de título ao portador tem direito à prestação nele indicada, mediante a sua simples apresentação ao devedor.

Parágrafo único. A prestação é devida ainda que o título tenha entrado em circulação contra a vontade do emitente.

Art. 909. O proprietário, que perder ou extraviar título, ou for injustamente desapossado dele, poderá obter novo título em juízo, bem como impedir sejam pagos a outrem capital e rendimentos.

Parágrafo único. O pagamento, feito antes de ter ciência da ação referida neste artigo, exonera o devedor, salvo se se provar que ele tinha conhecimento do fato. (BRASIL, 2002, Arts. 905 e 909). 
Rubens Requião sintetiza essa questão dizendo que “o Código de 1916 não se filiou puramente a nenhuma das duas teorias, temperando os rigores da teoria da criação com nuanças da teoria da emissão. Tal ecletismo foi mantido no Código Civil de 2002.” (REQUIÃO, 2008, p. 377).

Todavia, são as disposições da Lei Uniforme de Genebra (LUG) que devem prevalecer sobre as disposições do Código Civil (FERNANDES, 2015, p. 237), por se tratar de lei especial frente à lei geral. Dispõem os arts. 16 e 17 da LUG:

\begin{abstract}
Artigo 16: O detentor de uma letra é considerado portador legítimo se justifica o seu direito por uma série ininterrupta de endossos, mesmo se o último for em branco. Os endossos riscados consideram-se, para este efeito, como não escritos. Quando um endosso em branco é seguido de um outro endosso, presume-se que o signatário deste adquiriu a letra pelo endosso em branco.

Se uma pessoa foi por qualquer maneira desapossada de uma letra, o portador dela, desde que justifique o seu direito pela maneira indicada na alínea precedente, não é obrigado a restituí-la, salvo se a adquiriu de má-fé ou se, adquirindo-a, cometeu uma falta grave.

Artigo 17: As pessoas acionadas em virtude de uma letra não podem opor ao portador exceções fundadas sobre as relações pessoais delas com o sacador ou com os portadores anteriores, a menos que o portador ao adquirir a letra tenha procedido conscientemente em detrimento do devedor. (BRASIL, 1966, Arts. 16 e 17).
\end{abstract}

Com a sua análise, verifica-se que a LUG protege o terceiro de boa-fé, "o que deve prevalecer frente à proteção ditada pela lei civil para o que foi injustamente desapossado, tornando, assim, forte a inclinação do direito brasileiro pela teoria da criação" (FERNANDES, 2015, p. 237).

Nesse mesmo sentido, o caput do art. 24 da Lei n. 7.357/85 (Lei do Cheque): “desapossado alguém de um cheque, em virtude de qualquer evento, novo portador legitimado não está obrigado a restituí-lo, se não o adquiriu de má-fé." (BRASIL, 1985, Art. 24).

Surgem, assim, inúmeros questionamentos quanto à justiça nesses casos. Afinal, uma pessoa que teve um título de crédito furtado pode ser obrigada a pagá-lo? Juridicamente não há dúvidas de que se o portador do título estiver de boa-fé, conceito já explicado no capítulo anterior, ele terá direito ao cumprimento da obrigação, mas isso é justo? Seria justo também aquele que adquiriu o título de boa-fé perder seu direito? Sabe-se que a obrigação persiste por conta da preservação da segurança jurídica, então se faz necessário sopesar esses valores. 
A verdade é que no direito sempre estarão presentes as exigências da certeza e da equidade, ou segurança jurídica e justiça. A segurança jurídica e a certeza respondem à necessidade dos cidadãos de terem organicidade e unidade do sistema, de forma que o direito reduza a realidade social em esquemas simples e formais, ainda que a adequação não seja perfeita. A justiça e a equidade, por sua vez, respondem à necessidade de buscar o máximo de adequação possível entre o direito e a realidade, de modo que o direito não seja imutável e insensível. No entanto, é impossível estabelecer de forma a priori uma gradação entre esses valores, de sorte que eles se equilibrem de acordo com a situação de fato (ARAÚJO, 2010, p. 270).

Por isso são necessários os inúmeros mecanismos processuais visando ao máximo de equilíbrio entre esses valores. O ideal é que o Poder Judiciário se qualifique permanentemente para ter sempre um melhor discernimento no caso concreto, ponderando entre esses valores. Além disso, cita-se a garantia do duplo grau de jurisdição, que é a possibilidade de revisão de uma causa já julgada. Permite-se, com sua aplicação, que uma causa que tenha sido julgada de forma injusta ou errada seja reformada (CINTRA, 2005, p. 76). E como não é possível estabelecer qual valor será privilegiado no caso concreto de forma genérica, o juiz deverá sopesar esses valores, com a devida fundamentação.

Certo é que a finalidade dos títulos de crédito é justamente estabelecer a circulação do crédito com facilidade e segurança, servindo de prova entre as partes envolvidas. E segurança pressupõe evidência, ausência de dúvida, sendo a segurança jurídica um direito do cidadão, o que deve ser levado em conta no momento de se decidir um conflito. Na sua dimensão subjetiva, inclusive, é a proteção da confiança depositada nos negócios jurídicos e direitos em geral, para que não se altere direito patrimonial já consolidado, como ocorre na transferência de um título de crédito. Caminhando conjuntamente com essa segurança e inclusive contribuindo para ela, tem-se a formalidade, que, ao ser respeitada, traz mais credibilidade ainda ao instituto em estudo.

Por outro lado, têm-se os ideais de justiça e equidade que por ventura podem entrar em conflito com a segurança jurídica, como já afirmado. De acordo com a já mencionada classificação da Carolina Machado Cyrillo da Silva, a justiça geral ou legal seria a conformidade da conduta de um indivíduo à lei, que para Aristóteles podem ser regras escritas ou não. A equidade seria uma correção da justiça legal, isto é, aquilo que não está expresso na lei seria corrigido, sendo o meio-termo entre o excesso e a falta. 
Importante, ainda, retomar os conceitos estudados sobre a boa-fé, utilizada para satisfazer a equidade. Na boa-fé subjetiva, verifica-se o estado psicológico do indivíduo que crê ser titular de um direito, enquanto na objetiva, verifica-se uma crença no comportamento alheio, no sentido de que observa padrões de lisura e honestidade. E, observado o contexto da Constituição de 1988 e do Código Civil de 2002, a boa-fé deve ser preservada.

Portanto, quando se aplica a teoria da criação, preservando o direito do terceiro de boa-fé que se torna titular de um direito decorrente de um título de crédito furtado, está sendo privilegiada não só a segurança jurídica, mas também a justiça e equidade num todo. Embora o subscritor que não queria circular o título fique prejudicado, o saldo para a sociedade é positivo. Afinal, o subscritor do título tem ou deveria ter, como exigência legal, consciência das consequências que podem ter um descuido com um título assinado, todavia exigir que aquele que receba um título tenha conhecimento de toda sua origem atrapalharia profundamente a circulação de crédito no mercado. E, quando se dificulta a circulação de crédito, todo o desenvolvimento de um país fica prejudicado.

Além disso, garantiu-se ao subscritor o direito de restituição contra aquele que agiu de má-fé, garantindo a possibilidade de justiça para ele sem prejudicar a segurança jurídica da relação. Embora surja o problema da questão de provar, que pode ser difícil, não se pode transferir o ônus dessa verificação ao terceiro de boa-fé.

Poder-se-ia dizer que o mais justo seria ser nulo um título de crédito que circulou contra a vontade de seu subscritor, mas como saber disso se ele preenche todos os requisitos? Isso seria contrariar as características dos títulos de crédito e as razões de existirem.

Exige-se um direito certo para que não se tenha um direito ineficaz, o que não traria nem segurança jurídica e nem justiça. E a opção que foi feita pelo legislador é a de preservar o terceiro de boa-fé e a segurança jurídica que decorre dos títulos de crédito, sob pena de prejudicar todo o mercado e ai sim gerar injustiça maior.

\section{CONCLUSÕES}

Sabe-se que um país não consegue se desenvolver se não tiver um amplo e estável mercado de crédito, e os títulos de crédito tiveram o papel fundamental de conseguirem exteriorizar o crédito para que ele circule de forma rápida, ágil e segura, sendo de extrema relevância para o mercado. Mas um título de crédito, como nada no direito, deve estar acima 
de todos os valores de forma absoluta, sendo necessária uma análise nos casos concretos, visando sempre a um equilíbrio.

Neste trabalho, foi proposta a análise da relação entre a segurança jurídica e a justiça quando se analisam os títulos de crédito e as teorias da criação e da emissão. Dessa forma, fizeram-se alguns questionamentos, como: é justo alguém que teve um título de crédito furtado ser obrigado a pagá-lo? Por outro lado, considerando que o título circula, é justo aquele que recebeu o título e acredita que não haja nenhum problema com ele ser prejudicado porque se tratava de um título furtado?

Embora se trate de uma questão entre segurança jurídica e justiça, inevitavelmente deve-se fazer uma análise de mercado também. Ora, os títulos de crédito possuem como uma de suas principais características gerar a segurança jurídica, mas isso também não deve criar uma sensação de injustiça na sociedade. Porém, não se faz possível efetivar esses dois valores de forma plena e conjunta, então o legislador fez a opção de preservar os interesses do terceiro de boa-fé, que se traduz em confiança.

Em prol de uma circulação de crédito ágil, se os requisitos dos títulos de crédito estão preenchidos, não se deve dar àquele que receberá o título o ônus de verificar se ele teve algum problema de circulação, seja na origem ou em momento posterior. Como característica do próprio crédito, ele tem que confiar. Caso contrário, dificultaria essa circulação, trazendo mais custo e reflexos negativos nas negociações.

Mas se o possuidor do título está de má-fé, ai sim seria injustiça mantê-lo com o direito, senão o ordenamento jurídico estaria privilegiando a sua má-fé e o abuso em alguma situação. Então, entende-se que o legislador conseguiu conciliar os valores da segurança jurídica e da justiça na aplicação da teoria da criação com a sua mitigação quando se trata de um terceiro de má-fé.

Embora possa haver alguma sensação de injustiça quando alguém tem extraviado um título de crédito e é obrigado a pagar, é mais justo dar a ele o ônus de se preocupar e ter um zelo com o título, ao invés de passar esse ônus para aquele que receberá o título após sua circulação. Logo, individualmente pode haver uma injustiça num caso concreto, mas no geral são preservados com equilíbrio os valores da segurança jurídica e da justiça nesse contexto do direito brasileiro.

\section{REFERÊNCIAS}

ARAÚJO, Danilo Borges dos Santos Gomes de Araújo. O formalismo dos títulos de crédito como instrumento para a certeza da existência do Direito e para a segurança de sua 
realização: anotações a partir da bibliografia ascareliana. In: RODRIGUES, José Rodrigo; COSTA, Carlos Eduardo Batalha da Silva e; BARBOSA, Samuel Rodrigues (Coord.). Nas fronteiras do formalismo: a função social da dogmática jurídica hoje. São Paulo: Saraiva, 2010, p. 263-296.

ARAUUJO, Danilo Borges dos Santos Gomes de Araújo. O formalismo dos títulos de crédito como segurança jurídica. In: GORGA, Érica; SICA, Ligia Paula Pinto (Coord.). Estudos avançados em direito empresarial: títulos de crédito. Rio de Janeiro: Elsevier, 2013, p. 1-18.

ARISTÓTELES. Ética à Nicômaco. São Paulo: Martin Claret, 2001.

ASCARELLI, Tullio. Teoria Geral dos Títulos de Crédito. Campinas: Servanda, 2013.

BORGES, João Eunápio. Títulos de crédito. Rio de Janeiro: Forense, 1976.

BRASIL. Constituição da República Federativa do Brasil de 1988. Disponível em: <http://www.planalto.gov.br/ccivil_03/constituicao/constituicao.htm>. Acesso em: 13/06/15.

BRASIL. Constituição Politica do Imperio do Brazil (de 25 de março de 1824). Disponível em: <http://www.planalto.gov.br/ccivil_03/Constituicao/Constituicao24.htm>. Acesso em $18 / 06 / 2015$.

BRASIL. Decreto n. 57.663, de 24 de janeiro de 1966. Promulga as Convenções para adoção de uma lei uniforme em matéria de letras de câmbio e notas promissórias. Disponível em: $<$ http://www.planalto.gov.br/ccivil_03/decreto/Antigos/D57663.htm>. Acesso em: 26/06/2015.

BRASIL. Lei $n^{o}$ 10.406, de 10 de janeiro de 2002. Institui o Código Civil. Disponível em: <http://www.planalto.gov.br/ccivil_03/leis/2002/L10406.htm>. Acesso em 18/06/2015.

BRASIL. Lei $n^{o}$ 3.071, de $1^{\circ}$ de janeiro de 1916. Código Civil dos Estados Unidos do Brasil. Disponível em: <http://www.planalto.gov.br/ccivil_03/leis/L3071.htm>. Acesso em $18 / 06 / 2015$.

BRASIL. Lei $n$. 7.357, de 2 de setembro de 1985. Dispõe sobre o cheque e dá outras providências. Disponível em: <http://www.planalto.gov.br/ccivil_03/leis/17357.htm>. Acesso em: 26/06/2015.

BRASIL. Lei n. 9.784, de 29 de janeiro de 1999. Regula o processo administrativo no âmbito da Administração Pública Federal. Disponível em: <http://www.planalto.gov.br/ccivil_03/LEIS/L9784.htm>. Acesso em: 18/06/2015.

CEGALlA, Domingos Paschoal. Dicionário escolar da língua portuguesa. São Paulo: Companhia Editora Nacional, 2005.

CETIP. Estoque: ativos, títulos e derivativos. Disponível em: <https://www.cetip.com.br/boletimcetip>. Acesso em: 04/03/2015.

CINTRA, Antônio Carlos de Araújo; GRINOVER, Ada Pelegrini; DINAMARCO, Cândido Rangel. Teoria Geral do Processo. São Paulo: Malheiros, 2005. 
COELHO, Fábio Ulhoa. Títulos de Crédito Eletrônicos. Entrevista concedida ao Jornal Carta Forense em 02/02/2010. Disponível em: <http://www.cartaforense.com.br/conteudo/entrevistas/titulos-de-credito-eletronicos/5199>. Acesso em 23/07/2015.

COSTA, Wille Duarte. Títulos de crédito. $4^{\mathrm{a}}$ ed. Belo Horizonte: Del Rey, 2007.

FERNANDES, Jean Carlos. Teoria contemporânea dos títulos de crédito: imperativos principiológicos sob a ótica das teorias pós-positivistas. Belo Horizonte: Arraes, 2012.

FERNANDES, Jean Carlos. Direito empresarial contemporâneo. Rio de Janeiro: Lumen Juris, 2015.

FERRAZ JÚNIOR, Tércio Sampaio. Introdução ao Estudo do Direito: técnica, decisão, dominação. $5^{\text {a }}$ ed. São Paulo: Atlas, 2007.

GOMES, Orlando. Introdução ao Direito Civil. 12a ed. Rio de Janeiro: Forense, 1996.

LUCCA, Newton de. Aspectos da teoria geral dos títulos de crédito. São Paulo: Livraria Pioneira, 1979.

MIRANDA, Pontes de. Tratado de direito cambiário. Vol. 1. $2^{\mathrm{a}}$ ed. Campinas: Bookseller, 2001.

MOREIRA, José Davi Cavalcante. Aspectos da segurança jurídica no Brasil. Dissertação Mestrado em Direito da Universidade Federal do Ceará, Fortaleza, 2010, 164 p.

NORONHA, Fernando. O direito dos contratos e seus princípios fundamentais. São Paulo: Saraiva, 1994.

PATROCÍNIO, Daniel Moreira do. Direito Empresarial: teoria geral, direito societário, títulos de crédito, recuperação de empresa, falência. São Paulo: Juarez de Oliveira, 2009.

PERELMAN, Chaim. Ética e Direito. São Paulo: Martins Fontes, 2000.

PONT, Manuel Broseta. Manual de Derecho Mercantil. Vol. II. 14 ${ }^{\mathrm{a}}$ ed. Madrid: Tecnos, 2007.

REQUIÃO, Rubens. Curso de direito comercial. Vol. 2. 25 a ed. São Paulo: Saraiva, 2008.

ROCHA, Cármen Lúcia Antunes. O Princípio da Coisa Julgada e o Vício da Inconstitucionalidade. In: ROCHA, Carmem Lúcia Antunes (Org). Constituição e Segurança Jurídica: Direito Adquirido, Ato Jurídico Perfeito e Coisa Julgada - Estudos em Homenagem a José Paulo Sepúlveda Pertence. Belo Horizonte: Fórum, 2004.

ROSENVALD, Nelson; FARIAS, Cristiano Chaves de. Direito dos Contratos. Rio de Janeiro: Lumen Juris, 2011.

SADDI, Jairo. Crédito e Judiciário no Brasil: uma análise de Direito e Economia. São Paulo: Quartier Latin, 2007. 
SILVA, Carolina Machado Cyrillo da. Chaim Perelman: da argumentação à justiça um retorno a Aristóteles. Dissertação - Mestrado em Direito da Universidade Federal de Santa Catarina, Florianópolis, 2005, 115 p. 